\title{
KONTRIBUSI IBU RUMAH TANGGA TERHADAP PENDAPATAN KELUARGA DI DESA KINILOW KECAMATAN TOMOHON UTARA
}

\author{
R.M. Kumaat
}

\begin{abstract}
This research aims to study the contribution of housewives bamboo craftsman anya-man against the Village Kinilow family income in North Tomohon District.

The benefits of this research that can be used as information material for students who want to know more about the activities of the housewife in supporting family income and consideration for future research.

The results showed that the contribution of IRT when viewed on the basis of the husband's occupation IRT greatest contribution was the kind of husband's job as a motorcycle that is equal to 46.29 percent. Also the results showed that the contribution of IRT to the family income by an average of 36.05 per cent, 46.22 per cent while the contribution of the husband, and the contribution of children to family income is equal to 17.73 percent.
\end{abstract}

Keywords: Contributions, Housewife, Family Income

\section{PENDAHULUAN}

Wanita pada umumnya mempunyai peran ganda, baik bagi wanita yang berpendidikan rendah maupun wanita intelektual. Bagi wanita yang berpendidikan formal yang relative rendah, peran ganda itu didorong oleh kebutuhan ekonomi keluarga, dan untuk wanita intelektual peran ganda itu diarahkan pada pengembangan karier.

Sektor industry kecil merupakan usaha bagi sebagian masyarakat pedesaan karena dapat member peluang kerja, khususnya bagi ibu rumah tangga, dimana ia dapat mengerjakannya sambil mengawasi anak-anaknya di rumah.

Aktifitas wanita untuk memperoleh penghasilan pada dasarnya untuk memenuhi kebutuhan ekonomi keluarga. Hal ini karena kondisi rumah tangga pada lapisan bawah memerlukan sumber penghasilan ganda jika hanya dari penghasilan bapak atau kepala rumah tangga tidak mencukupi untuk memenuhi seluruh kebutuhan keluarga. Hal ini mendorong ibu dan anak-anak untuk turut menyumbangkan penghasilannya kedalam penghasilan keluarga. Dengan demikian diharapkan dapat meningkatkan kesejahteraan keluarga.
Banyak cara ditempuh dalam hubungannya sebagai pencari nafkah. Salah satu pekerjaan yang dilakukan oleh sebagian kaum wanita di Desa Kinilow Kecamatan Tomohon Utara adalah membuat kerajinan rumah tangga berupa alat perlengkapan dapur seperti anyaman nyiru dan bakul. Menurut data desa terdapat \pm 100 tenaga kerja wanita yang mengusahakan kerajinan tersebut.

Kerajinan anyaman bambu nyiru dan bakul merupakan salah satu komoditi yang mempunyai peluang yang baik bagi peningkatan kesejahteraan keluarga masyarakat. Kerajinan anyaman bambu merupakan suatu karya yang dikerjakan memakai peralatan yang sederhana dengan mengandalkan keterampilan.

Kerajinan anyaman bambu nyiru dan bakul dulunya dilakukan untuk sekedar kegemaran pengisi waktu luang setelah pulang dari kebun atau sebelum tidur. Hasil yang diperoleh bukan hanya untuk memenuhi keperluan rumah tangga, tetapi dapat di tabung atau disimpan untuk keperluan di masa depan. Kebutuhan akan anyaman bambu oleh masyarakat semakin dirasakan manfaatnya sehingga berangsur-angsur 
dari keterampilan untuk mengisi waktu luang ternyata telah beralih menjadi sumber pendapatan.

\section{Perumusan Masalah}

Peranan wanita dalam usaha mencari nafkah secara langsung dapat dilihat dalam keterlibatan membantu suaminya bekerja sebagai pengrajin anyaman bambu. Berdasarkan hal tersebut, maka yang menjadi permasalahan adalah : berapa besar kontribusi ibu rumah tangga pengrajin anyaman bambu terhadap pendapatan keluarga.

\section{Tujuan dan Manfaat Penelitian}

Penelitian ini bertujuan untuk mempelajari besarnya kontribusi ibu rumah tangga pengrajin anyaman bambu terhadap pendapatan keluarga di Desa Kinilow Kec. Tomohon Utara.

Adapun manfaat dari penelitian ini yaitu dapat dijadikan sebagai bahan informasi bagi mahasiswa yang ingin mengetahui lebih lanjut tentang aktivitas ibu rumah tangga dalam menunjang pendapatan keluarga dan sebagai bahan pertimbangan untuk penelitian selanjutnya.

\section{TINJAUAN PUSTAKA}

\section{Tanaman Bambu}

Bambu adalah tumbuhan yang batangnya berbentuk buluh, beruas, berbuku-buku, berongga, mempunyai cabang berimpang dan mempunyai daun bambu yang menonjol. Pemanfaatannya cukup luas dan sudah berlangsung lama. Akhir-akhir ini bambu telah masuk ke pasar dunia dalam bentuk pulp untuk bahan kertas, perekat, papan bambu lapis dan rebung kalengan. Di Asia Tenggara bambu dimanfaatkan juga untuk membuat bangunan, bermacam-macam hasil kerajinan dan alat music tradisional (Sutarno, H. 1996).

\section{Peranan Wanita}

Peranan wanita lebih banyak menunjukkan pada fungsi penyesuaian diri dan sebagai proses yang dilaksanakan oleh seseorang untuk menduduki posisi atau tempat dalam masyarakat (Ihromi, 1990).

Keikutsertaan wanita dalam meningkatkan kesejahteraan keluarga serta memajukan daerahnya merupakan perwujudan dari perannya dalam menunjang pembangunan (Anonimous, 1999). Sajogjo Pudjiwati (1983) mengemukakan bahwa peranan wanita dibedakan antara peranan wanita dalam masyarakat dan peranan wanita berkaitan erat dengan status kedudukannya dalam rumah tangga maupun masyarakat.

\section{Wanita yang Bekerja dalam Kedudukannya Sebagai Pencari Nafkah}

Bekerja adalah kegiatan yang dilakukan seseorang baik secara langsung maupun tidak langsung maupun tidak langsung untuk mendapatkan penghasilan dalam bentuk uang, barang, atau jasa, mengeluarkan energy dan mempunyai nilai waktu (Ihromi, 1990). Bagi keluarga petani, bekerja adalah kegiatan untuk memperoleh pendapatan guna memperoleh pendapatan guna memenuhi kebutuhan hidup keluarga.

Peranan wanita sebagai pencari nafkah, mempunyai tugas dan fungsi dalam mendukung kehidupan keluarga. Dengan semakin banyaknya kebutuhan akan rumah tangga maka kesempatan kerja untuk setiap keluarga terutama peran wanita dalam membantu pendapatan keluarga semakin tinggi (Soemarsono, 1995).

Bekerjanya wanita di luar rumah untuk kegiatan yang menghasilkan umumnya didorong oleh keadaan yang mengharuskan seorang wanita berperan ganda yaitu sebagai ibu rumah tangga dan sebagai pekerja keluarga untuk mencari nafkah dan untuk memnuhi kebutuhan keluarganya karena pendapatan yang diperoleh oleh suaminya dirasakan kurang mencukupi (Anonimous, 1996).

Beberapa faktor yang memmungkinkan wanita untuk bergerak luwes di bidang usahanya (Munandar, 1985), yaitu:

1. Faktor Sosial

- Faktor lingkungan yaitu usaha yang dilakukan oleh wanita yaitu yang usahanya turun temurun,

- Factor adat istiadat, misalnya wanita-wanita memegang peranan penting dalam mengelola ekonomi rumah tangga

2. Faktor Psikologis

Misalnya hal-hal yang berhubungan dengan kecantikan lebih condong dipegang oleh wanita. 
3. Faktor Ekonomi

Misalnya bila keadaan ekonomi keluarga kurang atau tidak mencukupi biasanya kaum wanita akan berusaha bekerja untuk memperoleh tambahan pendapatan bagi keluarga dengan membuka usaha kecil-kecilan.

Faktor-faktor yang menyebabkan wanita di pedesaan cenderung untuk memasuki industry kecil diantaranya, yaitu:

1. Karena industry kecil tidak memerlukan keahlian tinggi

2. Tidak menggunakan pendidikan formal yang tinggi

3. Jam kerja lebih luwes

Perempuan sebagai salah satu anggota keluarga, seperti anggota keluarga yang lain mempunyai tugas dan fungsi dalam mendukung kehidupan keluarga. Sebagian besar kontribusi yang diberikan oleh perempuan lebih kecil dibanding suami, oleh karena itu disarankan kepada perempuan untuk lebih dapat ditingkatkan produktivitas kerja agar supaya penghasilan setiap bulannya dapat bertambah, sehingga dapat memperoleh hasil yang lebih maksimal (Kumolontang, L.V, 2009).

\section{Industri Kecil}

Bila ditinjau dari segi usahanya maka peranan industry kecil dan kerajinan mampu menyerap tenaga kerja sehingga perlu ditingkatkan untuk memenuhi kebutuhan rumah tangga dan masyarakat. Demikian juga industry rumah tangga yang informal atau tradisional terus diarahkan dan tingkatkan sehingga dapat memperluas lapangan kerja, kesempatan berusaha dan peningkatan pendapatan masyarakat (Kamaluddin, 1992). Ciri-ciri industry kecil adalah:

1. Jumlah tenaga kerja kurang dari 5 orang

2. Tenaga kerja kebanyakan dari keluarga sendiri, kadang tidak diberi upah dan hubungan antara tenaga kerja dan pemiliknya kadang tidak formal

3. Menggunakan teknologi yang sngat sederhana, tradisional dan tidak banyak menggunakan mesin.

4. Bahan baku yang digunakan umumnya berasal dari desa setempat atau desa sekitarnya
5. Pemasaran biasanya masih secara sederhana dengan daerah yang tidak terlalu luas (Anonimous, 1996).

\section{METODOLOGI PENELITIAN}

\section{Metode Pengumpulan Data}

Penelitian ini menggunakan data primer dan data sekunder. Data primer diperoleh dari wawancara langsung dengan responden berdasarkan daftar pertanyaan dalam bentuk kuesioner, data sekunder diperoleh dari instansiinstansi yang terkait dengan penelitian ini.

\section{Metode Pengambilan Sampel}

Metode pengambilan sampel dalam penelitian ini diambil secara simple random sampling (acak sederhana). Dimana sampel yang diambil sebanyak 25 ibu rumah tangga pengrajin anyaman bambu yang masih mempunyai suami di Desa Kinilow Kec. Tomohon Utara.

\section{Konsep Pengukuran Variabel}

1. Karakteristik demografis

a. Umur (tahun)

b. Jumlah tanggunan (org)

c. Pendidikan formal dan non formal

2. Jenis pekerjaan suami

3. Jenis pekerjaan anak

4. Upah dari jenis-jenis anyaman yang diproduksi

5. Jumlah anyaman/responden/bulan

6. Pendapatan dalam keluarga

a. Pendapatan isteri dalam industry kecil anyaman bambu (Rp/bulan)

b. Pendapatan suami (Rp/bulan)

c. Pendapatan anak yang sudah bekerja (Rp/bulan)

\section{Analisis Data}

Data akan dianalisis secara deskriptif yang akan dikumpulkan dan disajikan dalam bentuk table. Dan untuk mengetahui kontribusi ibu rumah tangga terhadap pendapatan keluarga mengunakan analisis berikut:

\section{Kontribusi Ibu Rumah Tangga $($ IRT $)=$}

Pendapatan IRT dari Usaha Anyaman Bambu Pendapatan Keluarga 
dimana:

Pendapatan keluarga $=($ Pendapatan suami + pendapatan isteri + pendapatan anak yang sudah bekerja)

\section{Waktu dan Tempat Penelitian}

Penelitian ini dilaksanakan selama tiga bulan yaitu mulai bulan Oktober 2009 sampai bulan Desember 2009. Mulai dari persiapan, pengumpulan data, sampai penyusunan laporan akhir penelitian. Tempat penelitian dilakukan di Desa Kinilow Kec. Tomohon Utara.

\section{Kontribusi Ibu Rumah Tangga dalam Pendapatan Keluarga}

Jenis anyaman yang dikerjakan oleh ibu rumah tangga selama satu bulan untuk usaha/industry anyaman bambu.

Tabel 1. Rata-rata Jumlah Anyaman yang Dibuat oleh IRT per Jenis Anyaman

\begin{tabular}{|l|l|c|c|}
\hline No. & \multicolumn{1}{|c|}{$\begin{array}{c}\text { Jenis } \\
\text { Anyaman }\end{array}$} & $\begin{array}{c}\text { Jumlah } \\
\text { Prod/Bln }\end{array}$ & $\begin{array}{c}\text { Upah } \\
\text { (Rp)/unit }\end{array}$ \\
\hline 1. & Nyiru kecil & 33 & 5000 \\
2. & Nyiru besar & 25 & 7500 \\
3. & Bakul kecil & 30 & 5000 \\
4. & Bakul besar & 21 & 7500 \\
5. & Tempat buah & 13 & 5000 \\
6. & Tempat parsel & 7 & 7500 \\
\hline & Jumlah & 129 & \\
\hline
\end{tabular}

Tabel 1 menunjukkan bahwa jumlah anyaman yang paling banyak dianyam/dibuat oleh ibu rumah tangga yaitu nyiru kecil sebanyak 33 unit dan bakul kecil sebanyak 30 unit dengan upah masing-masing anyaman Rp. 5000 per unit. Jenis anyaman paling sedikit yang dibuat oleh ibu rumah tangga yaitu jenis anyaman tempat parsel sebanyak 7 unit dengan harga per unit Rp. 7500 .

Dari jenis pekerjaan dan banyaknya yang dibuat dengan harga per unit dari masing-masing anyaman dapat dilihat rata-rata pendapatan IRT.
Table 2 menunjukkan bahwa rata-rata pendapatan ibu rumah tangga yang paling besar ada pada jenis anyaman nyiru besar yaitu sebesar Rp. 186.000 per bulan. Hal ini disebabkan karena upah yang diterima oleh ibu rumah tangga dari satu unit anyaman nyiru besar lebih besar dari anyaman yang lebih kecil, sedangkan rata-rata jumlah pendapatan ibu rumah tangga yang paling sedikit ada pada jenis tempat parsel.

Table 2. Rata-rata Pendapatan IRT per Jenis Anyaman

\begin{tabular}{|l|l|r|r|}
\hline No. & \multicolumn{1}{|c|}{$\begin{array}{c}\text { Jenis } \\
\text { Anyaman }\end{array}$} & $\begin{array}{c}\text { Jumlah } \\
\text { Pendapatan } \\
(\mathrm{Rp})\end{array}$ & $\begin{array}{c}\text { Pendapatan } \\
\text { Rata-rata } \\
\text { per Bulan } \\
(\mathrm{Rp})\end{array}$ \\
\hline 1. & Nyiru kecil & 4.175 .000 & 167.000 \\
2. & Nyiru besar & 4.650 .000 & 186.000 \\
3. & Bakul kecil & 3.775 .000 & 151.000 \\
4. & Bakul besar & 3.900 .000 & 156.000 \\
5. & Tempat buah & 1.575 .000 & 63.000 \\
6. & Tempat parsel & 1.350 .000 & 54.000 \\
\hline & Jumlah & 19.425 .000 & 777.000 \\
\hline
\end{tabular}

Walaupun tempat parsel upah pembuatannya lebih besar tetapi jumlah yang dibuat terbatas mengikuti pesanan. Jumlah pendapatan responden secara keseluruhan Rp. 19.425.000 dengan hasil rata-rata adalah sebesar Rp. 777.000.

Table 3. Tingkat Pendapatan Responden per Bulan

\begin{tabular}{|c|c|c|}
\hline $\begin{array}{c}\text { Pendapatan } \\
(\mathrm{Rp})\end{array}$ & $\begin{array}{c}\text { Jumlah } \\
(\text { Org })\end{array}$ & $\begin{array}{c}\text { Persentase } \\
(\%)\end{array}$ \\
\hline $600.000-700.000$ & 3 & 12 \\
$701.000-800.000$ & 13 & 52 \\
$801.000-900.000$ & 8 & 32 \\
$901.000-1.000 .000$ & 1 & 4 \\
\hline Jumlah & 25 & 100 \\
\hline
\end{tabular}

Berdasarkan data yang ada pada Tabel 3 persentase terbanyak ada pada tingkat pendapatan Rp. 701.000-Rp. 800.000 yaitu sebanyak 52 persen, sedangkan persentase terkecil ada pada tingkat pendapatan Rp. 901.000 - Rp. 1.000 .000 yaitu sebanyak 4 persen.

Tabel 4 menunjukkan bahwa total pendapatan keluarga terbesar ada pada jenis pekerjaan suami sebagai petani yakni sebesar Rp. 
26.261.500 sedangkan total pendapatan terkecil ada pada jenis pekerjaan peternak yakni Rp. 6.175.000. Dari data pada Tabel 4, maka dapat kita hitung kontribusi masing-masing anggota keluarga berdasarkan jenis pekerjaan suami dan dapat dilihat pada Tabel 5.

Tabel 4. Total Pendapatan Anggota Keluarga Menurut Jenis Pekerjaan Suami

\begin{tabular}{|l|l|r|r|r|r|r|}
\hline \multirow{2}{*}{ No. } & \multirow{2}{*}{$\begin{array}{c}\text { Jenis Pekerjaan } \\
\text { Suami }\end{array}$} & \multirow{2}{*}{$\begin{array}{c}\mathrm{Jlh} \\
\text { (org) }\end{array}$} & \multicolumn{3}{|c|}{ Total masing-masing pendapatan } & \multirow{2}{*}{$\begin{array}{c}\text { Total pendapatan } \\
\text { keluarga (Rp) }\end{array}$} \\
\cline { 4 - 6 } & & \multicolumn{1}{|c|}{ Suami } & Isteri & \multicolumn{1}{|c|}{ Anak } & \\
\hline 1. & Petani & 12 & 13.000 .000 & 8.961 .500 & 4.300 .000 & 26.261 .500 \\
2. & Pengrajin & 6 & 5.950 .000 & 4.712 .500 & 3.700 .000 & 14.362 .500 \\
3. & T. ojek & 4 & 3.000 .000 & 3.275 .000 & 800.000 & 7.075 .000 \\
4. & Peternak & 3 & 2.950 .000 & 2.475 .000 & 750.000 & 6.175 .000 \\
\hline & Jumlah & 25 & 24.900 .000 & 19.424 .000 & 9.550 .000 & 53.874 .000 \\
\hline
\end{tabular}

Tabel 5. Kontribusi Anggota Keluarga Menurut Jenis Pekerjaan Suami

\begin{tabular}{|c|c|c|c|c|c|c|}
\hline \multirow[b]{2}{*}{ No. } & \multirow[b]{2}{*}{$\begin{array}{l}\text { Jenis Pekerjaan } \\
\text { Suami }\end{array}$} & \multirow[b]{2}{*}{ Jlh (org) } & \multirow{2}{*}{$\begin{array}{l}\text { Total } \\
\text { Pendapatan } \\
\text { Keluarga } \\
\text { (Rp) }\end{array}$} & \multicolumn{3}{|c|}{ Kontribusi (\%) } \\
\hline & & & & Suami & Isteri & Anak \\
\hline 1. & Petani & 12 & 26.261 .500 & 49,50 & 34,12 & 16,37 \\
\hline 2. & Pengrajin & 6 & 14.362 .500 & 41,43 & 32,81 & 25,76 \\
\hline 3. & Tukang ojek & 4 & 7.075 .000 & 42,40 & 46,29 & 11,31 \\
\hline 4. & Peternak & 3 & 6.175 .000 & 47,77 & 40,08 & 12,15 \\
\hline & Jumlah & 25 & 53.874 .000 & & & \\
\hline
\end{tabular}

Table 5 menunjukkan bahwa kontribusi ibu rumah tangga terhadap pendapatan keluarga yang paling besar terdapat pada jenis pekerjaan suami sebagai tukang ojek yaitu sebesar 46,29 persen. Sedangkan kontribusi ibu rumah tangga yang paling sedikit ada pada jenis pekerjaan suami sebagai pengrajin yaitu sebesar 32,18 persen.

Table 6 dapat dilihat kontribusi isteri sebesar 36,05 persen, sedangkan suami sebesar 46,22 persen. Ini menunjukkan bahwa kontribusi isteri lebih kecil daripada kontribusi suami untuk menunjang pendapatan keluarga. Rendahnya pendapatan isteri dikarenakan para isteri mengerjakan pekerjaan pada industry anyaman bambu setelah menyelesaikan pekerjaannya di rumah sebagai ibu rumah tangga seperti memasak, mencuci dan mengurus anak dan setelah itu mengerjakan pekerjaan menganyam untuk menunjang pendapatn keluarga. Untuk kontribusi anak paling sedikit yakni sebesar 17,73 persen hal ini disebabkan tidak semua anak dari responden yang sudah memiliki pekerjaan sehingga belum dapat memberikan kontribusi untuk menunjang pendapatan keluarga.

Tabel 6. Kontribusi Rata-rata Anggota Keluarga Terhadap Pendapatan Keluarga

\begin{tabular}{|l|r|r|r|}
\hline $\begin{array}{l}\text { Anggota } \\
\text { keluarga }\end{array}$ & $\begin{array}{c}\text { Total } \\
\text { pendapatan }\end{array}$ & $\begin{array}{c}\text { Rata-rata } \\
\text { pendapatan } \\
(\mathrm{Rp})\end{array}$ & $\begin{array}{c}\text { Kontribu } \\
\text { si (\%) }\end{array}$ \\
\hline Suami & 24.900 .000 & 996.000 & 46,22 \\
Isteri & 19.424 .000 & 776.960 & 36,05 \\
Anak & 9.550 .000 & 795.833 & 17,73 \\
\hline
\end{tabular}

\section{KESIMPULAN DAN SARAN}

\section{Kesimpulan}

1. Keterlibatan ibu rumah tangga dalam industry kecil anyaman bambu di Desa Kinilow hanya pada jenis kegiatan mengayam. Dan jenis 
anyaman yang paling banyak dikerjakan atau dibuat oleh IRT adalah jenis anyaman nyiru kecil dan bakul kecil.

2. Penerimaan pendapatan IRT yang paling besr ada pada jenis anyaman nyiru besar, dan pendapatan yang diterima IRT yang paling sedikit ada pada jenis anyaman tempat parsel.

3. Kontribusi IRT jika dilihat berdasarkan dari jenis pekerjaan suami maka kontribusi IRT yang paling besar ada pada jenis pekerjaan suami sebagai tukang ojek yaitu sebesar 46,29 persen.

4. Kontribusi IRT terhadap pendapatan keluarga rata-rata sebesar 36,05 persen, sedangkan kontribusi suami 46,22 persen, dan kontribusi anak terhadap pendapatan keluarga adalah sebesar 17,73 persen.

\section{Saran}

1. Usaha kerajinan anyaman bambu perlu dipertahankan dan tingkatkan usahanya ke dalam bentuk-bentuk atau jenis-jenis anyaman yang lain.

2. Untuk pemerintah kiranya dapat memperhatikan dan memberikan bantuan berupa pelatihan-pelatihan atau kursus-kursus ketrampilan agar supaya industry anyaman bambu ini dapat berkembang dan lebih kreatif dalam pembuatan model-model atau jenis-jenis anyaman.

3. Penelitian ini hendaknya dapat dijadikan patokan bagi ibu-ibu rumah tangga dalam mengerjakan sesuatu bahwa selain pekerjaan sebagai isteri dan ibu dalam keluarga dapat juga berperan dalam usaha mencari nafkah guna menambah pendapatan keluarga.

\section{DAFTAR PUSTAKA}

Anonymous, 1996. Kebijakan pengembangan industry kecil di Sulawesi Utara dalam penelitian repelita VI. Kantor Wilayah Perindustrian dan Perdagangan Propinsi Sulawesi Utara.

1999. GBHN Pendidikan dan Kebudayaan, Jakarta.

Kamaludin, 1992. Bunga Rampai Pembangunan Nasional dan Pembangunan Daerah. Fak. Ekonomi UI, Jakarta.

Munandar, 1982. Emansipasi dan Peranan Wanita. UI Press, Jakarta.

Mitardjo, 1982. Industri untuk menunjang peranana wanita dalam melaksanakan program kependudukan dan keluarga berencana. BPLP, Ujung Pandang.

Sajogyo, P. 1983. Peranan Wanita dalam Pembangunan Masyarakat Desa. CV. Rajawali, Jakarta.

Wahongan-Kosakoy, A.E. 1994. Wanita, Jender : Dalam Keluarga dan Masyarakat. Makalah dalam pidato pengukuhan guru besar dalam ilmu sosiologi pedesaan pada Fakultas Pertanian Unsrat Manado. 